This item was submitted to Loughborough's Research Repository by the author.

Items in Figshare are protected by copyright, with all rights reserved, unless otherwise indicated.

\title{
Online multiparameter estimation of nonsalient-pole PM synchronous machines with temperature variation tracking
}

PLEASE CITE THE PUBLISHED VERSION

http://dx.doi.org/10.1109/TIE.2010.2054055

PUBLISHER

(C) IEEE

VERSION

AM (Accepted Manuscript)

LICENCE

CC BY-NC-ND 4.0

\section{REPOSITORY RECORD}

Liu, Kan, Qiao Zhang, Jintao Chen, Zi-Qiang Zhu, and Jing Zhang. 2019. "Online Multiparameter Estimation of Nonsalient-pole PM Synchronous Machines with Temperature Variation Tracking”. figshare.

https://hdl.handle.net/2134/25041. 


\title{
Online Multi-parameter Estimation of Non-salient Pole PM Synchronous Machines with Temperature Variation Tracking
}

\author{
Kan Liu, Qiao Zhang, Jintao Chen, Member, IEEE, Z.Q. Zhu, Fellow, IEEE, and Jing Zhang
}

\begin{abstract}
The ill-convergence of multi-parameter estimation due to rank-deficient state equations of permanent magnet synchronous machines (PMSM) is investigated. It is verified that the PMSM model for multi-parameter estimation under $i_{d}=0$ control is rank-deficient for simultaneously estimating winding resistance, rotor flux linkage and winding inductance, and cannot ensure them to converge to correct parameter values. A new method is proposed based on injecting a short pulse of negative $i_{d}$ current and simultaneously solving two sets of simplified PMSM state equations corresponding to $i_{d}=0$ and $i_{d} \neq 0$ by using Adaline neural network. The convergence of solutions is ensured, while the minimum $\left|i_{d}\right|$ is determined from the error analysis for non-salient pole PMSM. The proposed method does not need the nominal value of any parameter and only needs to sample the winding terminal currents and voltages, and the rotor speed for simultaneously estimating the $d q$-axis inductances, the winding resistance and the rotor flux linkage in non-salient pole PMSM. Compared with existing methods, the proposed method can eliminate the estimation error caused by the variation of rotor flux linkage and inductance as a result of state change due to injected $d$-axis current in the surface-mounted PMSM (SPMSM). The method is verified by experiments and the results show that the proposed method has negligible influence on the output torque and the rotor speed, and has good performance in tracking the variation of PMSM parameters due to temperature variation.

Index Terms - temperature, Adaline, parameter estimation, PMSM, stator winding resistance, rotor flux linkage, identification
\end{abstract}

\section{NOMENCLATURE}

\section{$R$ : $\quad$ Stator winding resistance $(\Omega)$.}

Manuscript received October 6, 2009. Revised April 23, 2010. Accepted for publication June 4, 2010.

Copyright (c) 2009 IEEE. Personal use of this material is permitted. However, permission to use this material for any other purposes must be obtained from the IEEE by sending a request to pubs-permissions@ieee.org.

This work was supported in part by the National Natural Science Foundation of China under Grant 60634020 and the first two authors acknowledge the financial support by the China Scholarship Council for their joint $\mathrm{PhD}$ programs at University of Sheffield, UK.

K. Liu and J. Zhang are with the School of Electrical and Information Engineering, Hunan University, China (e-mail: lkan@live.cn; zhangj@hnu.cn).

Q. Zhang is with the Department of Control Science and Engineering, Huazhong University of Science and Technology, China (e-mail: zq_zjuee@hotmail.com).

J.T. Chen and Z.Q. Zhu are with the Department of Electronic and Electrical Engineering, University of Sheffield, UK (e-mail: J.Chen@sheffield.ac.uk: Z.O.Zhu@sheffield.ac.uk).
$R_{p}$ : External resistance added in series with winding $(\Omega)$.

$L_{d}, L_{q}: d q$-axis inductance $(\mathrm{H})$.

$\Delta L: L_{q}-L_{d}=\Delta L(\mathrm{H})$.

$i_{d 0}$ : Actual $d$-axis current (A) under $i_{d}=0$ control.

$\psi_{m}\left(i_{d}\right)$ : Rotor flux linkage $(\mathrm{Wb})$.

$T$ : $\quad$ Rotor magnet temperature $\left({ }^{\circ} \mathrm{C}\right)$.

$T_{0}$ : Nominal rotor magnet temperature $\left({ }^{\circ} \mathrm{C}\right)$.

$\psi_{m 0}(T)=\psi_{m}\left(i_{d}=0, T\right)$ : Actual rotor flux linkage $(\mathrm{Wb})$ under $i_{d}=0$ control at rotor magnet temperature of $T$.

$\psi_{\text {me }}(T)$ : Estimated rotor flux linkage $(\mathrm{Wb})$ by proposed method under $i_{d}=0$ control at rotor magnet temperature of $T$.

$\Delta \psi_{m}\left(i_{d}\right)=\psi_{m 0}-\psi_{m}\left(i_{d}\right)$ : Rotor flux linkage variation (Wb) due to $i_{d} \neq 0$.

$\psi_{\text {merror }}$ : Estimation error $(\mathrm{Wb})$ caused by $\Delta \psi_{m}$ and $\Delta L$.

$\eta$ : Convergence factor of Adaline NN.

\section{INTRODUCTION}

P ermanent magnet synchronous machines (PMSM) are now widely employed in industrial servo drives, electric/hybrid electric vehicles, and wind power generators, etc., due to high power/torque density. It is important to obtain accurate machine parameters for online fault diagnosis and rotor/stator temperature monitoring, as well as for achieving high control performance, e.g. in determining the optimal current profile in order to achieve maximum torque per ampere control for electric vehicle application. Many methods have been proposed to obtain the parameters from the terminal signals and can be categorized and reviewed as follows.

\section{A. Online estimation}

Modern control theories, such as extended Kalman filter (EKF), model reference adaptive system (MRAS) and recursive least-square (RLS) algorithm and neural network (NN), can be used for online parameter estimation [1]-[12][14]-[24]. For example, [1]-[4] estimated the winding resistance and inductances without considering the rotor flux linkage estimation. [1] proposed a method based on the Lyapunov stability theorem for identifying the winding resistance and inductance in surface-mounted PMSM (SPMSM); [2] proposed a MRAS based resistance identification method for sensorless control; [3] proposed an online computing method for identifying the $d q$-axis inductances and winding resistance while the rotor flux linkage was set to the nominal value; In [4], the rotor flux linkage was regarded as a constant and a RLS 
method was applied for estimating the winding resistance and $d q$-axis inductances of surface-mounted and interior PMSM, respectively. Other works, such as [5]-[7], focused on estimating the rotor flux linkage as well as other parameters. In [5], two sensorless MRAS schemes were proposed for estimating the rotor flux linkage and winding resistance, respectively. However, [5] found that it was impossible to simultaneously identify three parameters (rotor speed, winding resistance and flux linkage) by two variables. Hence, [5] proposed to estimate the winding resistance and rotor flux linkage by two independent schemes. The problem in [5] also occurred in [6], in which an EKF was used for simultaneously identifying the winding resistance and rotor flux linkage. In addition, [7] proposed an online multi-parameter identification method based on addition power and torque measurement technique. Parameters such as copper loss, stator loss, mechanical loss and stray loss were correctly estimated although high accuracy digital power meter and torque transducer are required.

\section{B. Offline estimation}

Offline parameter estimation is easier for methods which require intensive computation, such as fast Fourier transform (FFT), evolutionary computation and EKF. Many researchers have focused on testing the parameters offline at standstill state of the machine since the standstill PMSM steady-state equations can eliminate the rotor flux linkage and hence the winding resistance can be easily estimated. For example, a DC step voltage [8] and AC square wave voltages [9] were injected into the PMSM machine at standstill for estimating the winding resistance and $d q$-axis inductances. In [10], a Particle Swarm Optimization based PMSM parameter identification method was proposed to offline estimate the resistance and rotor flux linkage. In [11], the fundamental components of phase current and voltage waveforms were extracted by FFT and the winding resistance was set to the nominal value, the $d q$-axis inductances were estimated by offline derivative computation. In [12], it proposed how to generate multi-sinusoidal test signals for identifying the PMSM parameters by a voltage-source inverter. In [13], it proposed how to offline estimate the iron loss of an induction machine by time-stepping finite element method.

\section{Hybrid estimation}

Hybrid offline and online parameter estimation was introduced recently [14][15]. In [14], the standstill rotor position was firstly obtained by injecting high-frequency current. With the estimated standstill rotor position, the winding resistance and $d q$-axis inductances were also estimated at standstill, while the rotor flux linkage was estimated at rotor rotating condition. In [15], the PMSM inductance, resistance and equivalent iron loss resistance were measured at standstill while the rotor flux linkage, inertia and viscous constants were estimated at rotating condition by an adaptive algorithm. Clearly, the offline hybrid estimation [8]-[14] method could not online track the parameter variation which may be caused by neglecting the magnet temperature rise and core loss [11].

\section{Rank-deficient problem}

If the rank of the steady state $d q$-axis equation is less than the number of parameters to be identified [1]-[6], the equation will be rank-deficient and the estimated results may not be ensured to converge to the correct values and exhibit significant error. For example, in [3][4][6], one equation was used for online estimating more than two parameters. Consequently, it was found in [3] that the estimated $R(6.3 \Omega)$ was much smaller than

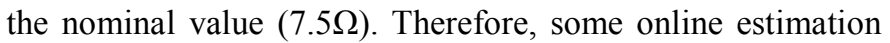
methods [1][2][5] were proposed to fix one or two parameters to nominal values in order to reduce the number of parameters to be estimated. Similarly, in [4], the $d q$-axis inductances and $R$ were estimated by setting the flux linkage to the nominal value.

In the control of PMSM, $i_{d}=0$ vector control is often employed. However, as will be shown later in Section II, when $i_{d}=0$ it is rank-deficient to simultaneously estimate $R$ and $\psi_{m}$ although the inductance can be independently estimated. When $i_{d} \neq 0$ it is also rank-deficient to simultaneously estimate $R, \psi_{m}$ and the inductance. However, in this case $\left(i_{d} \neq 0\right)$ if the inductance is set to be constant, the machine equation will be of full rank and can be used for simultaneously estimating $R$ and $\psi_{m}$ [17][18]. However, as will be shown in section II, the accuracy of such method will suffer from the actual variation of parameter(s) which is (are) fixed in the estimation.

In this paper, a new online estimation method is proposed by employing two sets of simplified non-salient pole PMSM state equations corresponding to $i_{d}=0$ and $i_{d} \neq 0$, whose solutions will not be ill-converged, while the accuracy of estimation is ensured by employing the minimum $\left|i_{d}\right|$ which is obtained from the error analysis for non-salient pole PMSM. Compared with existing methods using $i_{d} \neq 0$ [17][18][22], the proposed method can ensure the estimation errors in winding resistance and rotor flux linkage due to $L_{q} \neq L_{d}$ and the assumption of $\psi_{m}\left(i_{d} \neq 0\right)=\psi_{m}\left(i_{d}=0\right)$ to be negligible. Furthermore, the proposed method does not need the nominal value of any parameter and only needs to sample the winding terminal currents and voltages and the rotor speed to obtain the winding inductance, the winding resistance and the rotor flux linkage by using Adaline neural network [26].

The paper is organized as follows. Existing problems in multi-parameter estimation methods based on rank-deficient PMSM equations, such as why most estimators based on the rank-deficient PMSM equations are vulnerable to converge to the sub-optimum, rather than global optimum, will be discussed and investigated experimentally in section II. The proposed new online estimation method is presented in Section III, together with the error analysis for the simplification of PMSM state equations. The experimental validation on the prototype SPMSM under the conditions of step change in winding resistance and temperature rise is shown in section IV.

\section{RANK-DEFICIENT PROBLEMS IN PMSM MULTI-PARAMETER ESTIMATION}

In this section, the existing rank-deficient problem in PMSM multi-parameter estimation is highlighted and investigated. Although the estimation may be based on different reference 
frames, such as rotor reference frame ( $d q$-axis), stator reference frame ( $a \beta$-axis) and $a b c$-three-phase reference frame, similar rank-deficient problem exists. Therefore, for simplicity, it will focus on that based on the rotor reference frame.

\section{A. Rank-deficient Equations and Problems with Existing Methods}

Assuming that the PMSM has negligible cross-coupling magnetic saturation, structural asymmetry, iron losses, magnet eddy current loss, and harmonics in the descriptive functions of windings, rotor anisotropy and coercive force of magnets, the $d q$-axis equations of the PMSM are given by:

$$
\begin{aligned}
& \frac{d i_{d}}{d t}=-\frac{R}{L_{d}} i_{d}+\frac{L_{q}}{L_{d}} \omega i_{q}+\frac{u_{d}}{L_{d}} \\
& \frac{d i_{q}}{d t}=-\frac{R}{L_{q}} i_{q}-\frac{L_{d}}{L_{q}} \omega i_{d}+\frac{u_{q}}{L_{q}}-\frac{\psi_{m}}{L_{q}} \omega
\end{aligned}
$$

where $i_{d}, i_{q}, u_{d}$ and $u_{q}$ are the $d q$-axis stator currents and voltages; $\omega$ is the electrical angular speed; $R, L_{d}, L_{q}$ and $\psi_{m}$ are the stator resistance, the $d q$-axis inductances and the rotor flux linkage, respectively. In this paper, before estimation, the measured data including $d q$-axis currents, voltages and rotor speed are filtered by first-order Butterworth low-pass filters, respectively. Therefore, the average part of measured data can be obtained after filtering and will be used for subsequent estimation. After filtering, the parameter estimation can be based on the steady-state machine model [24], which can be expressed in the discrete form as:

$$
\begin{aligned}
& u_{d}(k)=R i_{d}(k)-L_{q} \omega(k) i_{q}(k) \\
& u_{q}(k)=R i_{q}(k)+L_{d} \omega(k) i_{d}(k)+\psi_{m} \omega(k)
\end{aligned}
$$

where ' $k$ ' is the index of the discrete sampling instant. Under $i_{d}$ $=0$ control, (2) can be simplified into:

$$
\begin{aligned}
& u_{d}(k)=-L_{q} \omega(k) i_{q}(k) \\
& u_{q}(k)=R i_{q}(k)+\psi_{m} \omega(k)
\end{aligned}
$$

Parameters, such as winding resistance, inductance and rotor flux linkage, are regarded as unknown parameters to be estimated. Other variables, such as $d q$-axis currents, voltages and electrical angular speed, are measured. Since there are more than two parameters in two equations, (2) can be regarded to be rank-deficient.

As winding resistance, inductance and rotor flux linkage usually vary with the load conditions, magnetic saturation and temperature rise etc., it will result in inaccurate estimation if they are not estimated at the same time. However, due to rank-deficiency, if the convergence speed of the algorithm is not appropriately controlled and/or the initial values are chosen not close to the actual values, ill-convergence may occur since there are infinite numbers of sub-optimum.

Therefore, no matter which estimation method, such as EKF, MRAS, NN and RLS, is employed for multi-parameter estimation, the rank of employed mathematical model should be considered first. Bearing this in mind, it can be found in literature that some researchers [16]-[22] tried to solve this problem and have made good contributions. For example, in [16], an additional torque equation was introduced by a load test and was combined with online estimation methods so that three parameters ( $d q$-axis inductances and the rotor flux linkage) could be estimated. In [17], the inductance was fixed to the nominal value and an error model was employed for resistance and rotor flux linkage estimation. Although it was novel to inject an alternating current signal in $d$-axis current for resistance and flux linkage estimation, the method could not account for the influence of inductance variation. In addition, no experimental results were presented for the resistance and rotor flux linkage. In [18], a fast estimation for rotor flux linkage based on PMSM reactive power by using $i_{d}<0$ control was proposed. Although it would cause flux weakening, its computation did not need to consider the winding resistance value. However, similar to [17], it did not account for inductance variation. In [19], a RLS based method was proposed for estimating the winding resistance, rotor flux linkage and inductance. However, during the estimation, it required periodic change in torque and could not be effective when the machine is at steady state. Consequently, the estimated inductance and rotor flux linkage would not be the same values as those under $i_{d}=0$ and $i_{q}=$ constant. In [20], a winding resistance estimation based on online injecting the DC current was proposed. It was novel to estimate the winding resistance without considering the rotor flux linkage, but it is still required to be verified by experiment. In [21], it proposed to estimate the stator winding resistance and rotor flux linkage at low speed and high speed, respectively. However, it could not estimate them simultaneously and required the rotor speed to be changed for estimation. In [22], it proposed to simultaneously estimate the stator winding resistance, $d q$-axis inductances and rotor flux linkage by injecting a three-level perturbation in the $d$-axis current. However, since its estimation was based on rank-deficient model, the experimental results showed that it still could not ensure the results to be converged to the correct values and actually will finally diverge.

In order to illustrate the problems in existing estimation methods based on rank-deficient PMSM equations, four schemes are introduced and investigated experimentally, the design of estimators being based on Adaline $\mathrm{NN}$ and described in Appendix A.

Scheme I: Adaline NN estimators for inductance and winding resistance, i.e. (A.3) and (A.4), are used, while the rotor flux linkage is fixed and set to its nominal value.

Scheme II: Adaline NN estimators for inductance and rotor flux linkage, i.e. (A.3) and (A.5), are used, while the winding resistance is fixed and set to its measured value.

Scheme III: Estimators, (A.3), (A.4) and (A.5), are used for simultaneously estimating the inductance, winding resistance and rotor flux linkage. The estimated winding resistance value of (A.4) and estimated rotor flux linkage value of (A.5) will be transferred to each other at every step of estimation.

Scheme IV: Step 1: The inductance value $\left(L_{d}=L_{q}\right)$ when $i_{d}=0$ is estimated by (A.3). Step 2: The inductance is set to the value estimated from the first step and a negative $i_{d}$ is injected. Since the inductance is set to be constant, the $d q$-axis equation when $i_{d}<0$ is of full rank for simultaneously estimating the winding resistance and rotor flux linkage. When $i_{d}<0$, the winding 
resistance can be estimated from $d$-axis equation by (A.6). Step 3: With the estimated winding resistance value, the rotor flux linkage can be then estimated by (A.5).

It is worth to note that Schemes I and II are similar to the two schemes proposed in [5], Scheme III is similar to the rank-deficient estimation method proposed in [3][6], whilst Scheme IV is similar to the schemes proposed in [17] and [18]. In addition, [4] is similar to Scheme II when it is used for the non-salient pole PMSM parameter estimation. However, [4] will be similar to Scheme III if it is used for salient-pole PMSM parameter estimation.

\section{B. Experimental Results and Analysis}

The above four schemes are verified on a vector controlled SPMSM drive system. The details of hardware drive platform as well as the prototype machine design parameters are given in Appendix B. In the experiment, the sampling period of drive control system and the update interval of all the estimation methods are set to be $83.3 \mu$ s. Since the measured signals such as rotor speed, $d q$-axis currents and voltages fluctuate around the values specified by the PI regulators, these signals are filtered by first-order Butterworth low-pass filters before estimation. Figs. 1(e) and (f) compare the results of Schemes I and II with and without first-order Butterworth low-pass filters. As can be seen, the estimated result with low pass filtering has no oscillation and converges very fast to the final value.

As can be seen from the estimated results of Schemes I and II in Figs. 1(a) and (c) which are similar to the two schemes in [5], it is evident that the two schemes are accurate compared with the nominal values given in Table I when the PMSM is at nominal temperature. However, after heating for 20 minutes, contrary to the actual variation trend which would be expected, the estimated rotor flux linkage becomes larger as a result of mismatching between actual and nominal winding resistance values, Fig. 1(b). The similar problem also occurs in Scheme II, the estimated winding resistance value $(0.421 \Omega)$ being less than the actual one $(0.456 \Omega)$ due to the mismatching between actual and nominal rotor flux linkages. Experimental results of Scheme III, Fig. 2(a), show that when the initial values of the three parameters to be estimated are far from the nominal values, the estimated winding resistance and rotor flux linkage are ill-converged into $0.895 \Omega$ and $67.0 \mathrm{mWb}$, respectively, which are significantly different from the nominal values in Table I. When the initial values are set to be the nominal values in Table I, it is still hard to ensure the estimated solutions always correct since there inevitably exist fluctuations in measured signals which may cause the estimation solution to slowly diverge into sub-optimum if the measured $d q$-axis data are not filtered. It is evident from Figs.2(b) and (c) that the estimated final results of $R$ and $\psi_{m}$ are still very sensitive to the convergence speed $(\eta)$ and low-pass filters, and may be converged to wrong values or even diverged. Even if the $d q$-axis data are filtered by low-pass filters, the convergence speed of estimators will also impact the estimation results, as shown in Fig. 2(b).

However, for the $q$-axis inductance $L_{q}$, it can be estimated independently from (3a), irrespective of the estimated values of winding resistance and rotor flux linkage. Further, (3a) is of full rank. Therefore, it can be uniquely determined by the measured $d$-axis voltage, $q$-axis current and rotor speed. This is confirmed in Figs. 2(a)-(c), in which the estimated $q$-axis inductance values $L_{q}\left(i_{d}=0\right)$, are all converged to the same result.

Experiment results of Scheme IV, Fig. 3, show that if the $d q$-axis inductances are both set to $L_{q}\left(i_{d}=0\right)$, the estimated winding resistance and rotor flux linkage will be different from the nominal value and vary due to different $i_{d}$. This is due to the inductance variation as well as the difference between $L_{d}$ and $L_{q}$ caused by $i_{d}(\neq 0)$. [17] and [18] are based on the similar principle of Scheme IV, both assuming that $L_{d}=L_{q}$ and the inductance will not change with $i_{d}$. Consequently, they will have the same problem as Scheme IV.

By the way, the ill-convergence phenomenon did occur in some existing papers, such as [3][4][6]. However, in [4], it guessed that it was caused by nonlinearity, while in [3] it guessed that it was caused by modeling error but without further explanation. When the PMSM machine is modeled in the stator $a b c$ or $a \beta$-axis reference frame, similar rank-deficient problem also exists [6].

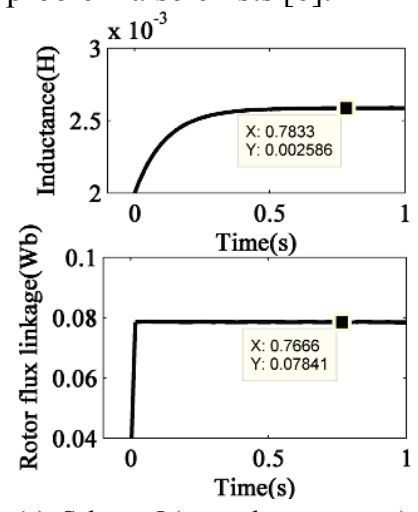

(a) Scheme I (normal temperature).
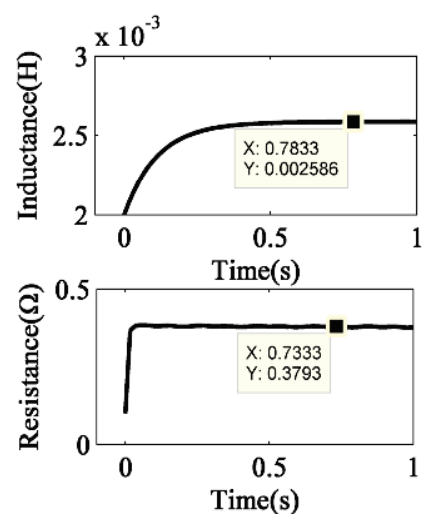

(c) Scheme II (normal temperature).

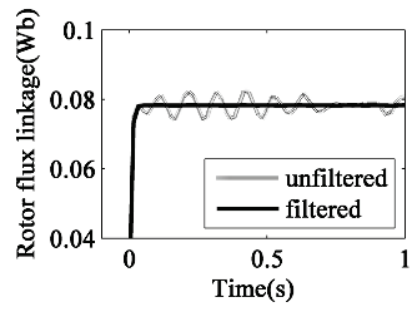

(e) Scheme I.

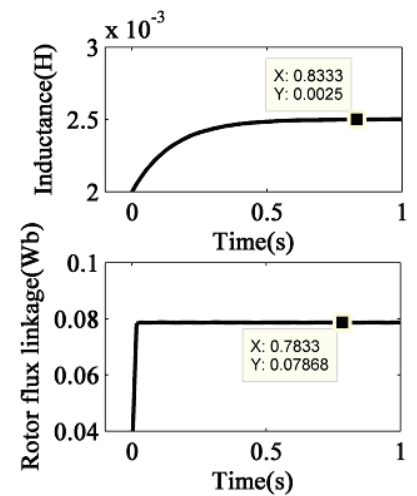

(b) Scheme I (after heating for 20 minutes).

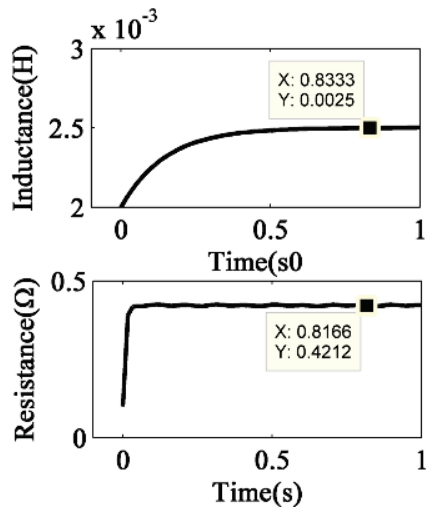

(d) Scheme II (heating for 20 minutes).

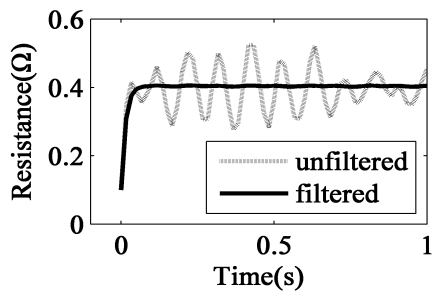

(f) Scheme II.
Fig. 1. Estimated results of Scheme I and Scheme II. 


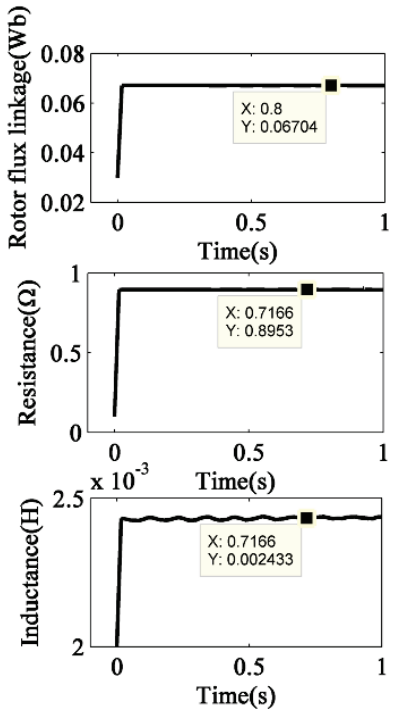

(a) Initial values far from actual values
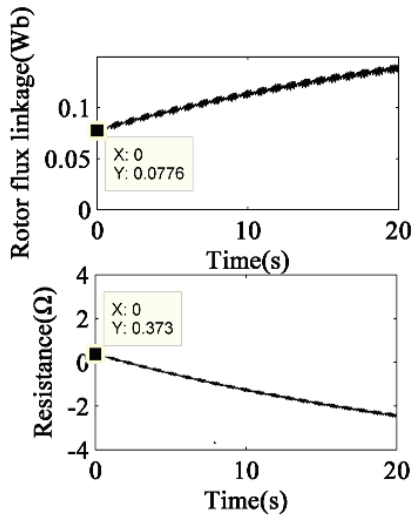

(c) Similar to (b) but without low-pass filtering for sampled signals

Fig. 2. Simultaneously estimated resistance, inductance and rotor flux linkage by Scheme III.
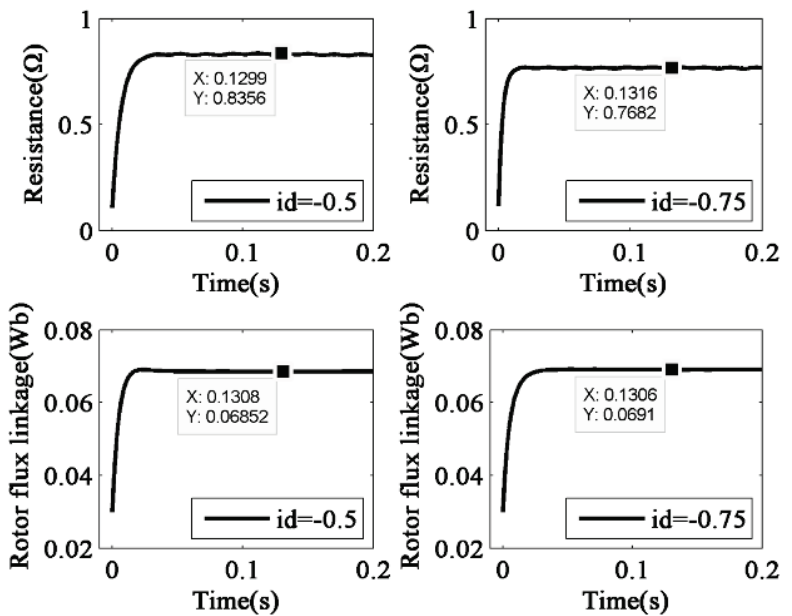

Fig. 3. Estimated results of Scheme IV (when $i_{d}=-0.5$ and $i_{d}=-0.75$ ).

\section{PROPOSED METHOD}

In this section, a new method to simultaneously online estimate the winding inductance, the winding resistance and the rotor flux linkage under $i_{d}=0$ control will be proposed to overcome the foregoing problems which are associated with the rank-deficient equations of PMSM.

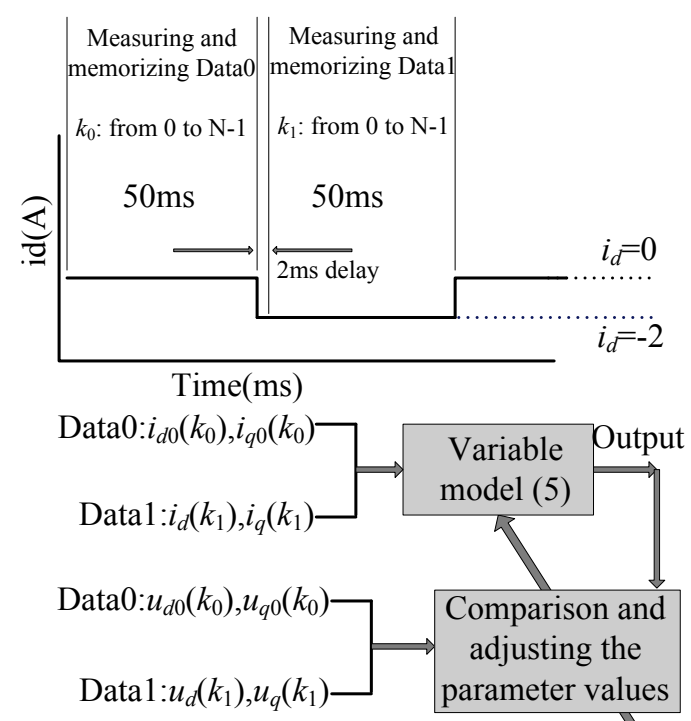

Make $k=k_{0}=k_{1}$ and input from 0 to $\mathrm{N}-1$ in sequence

(a) Process of sampling, memorizing and estimation

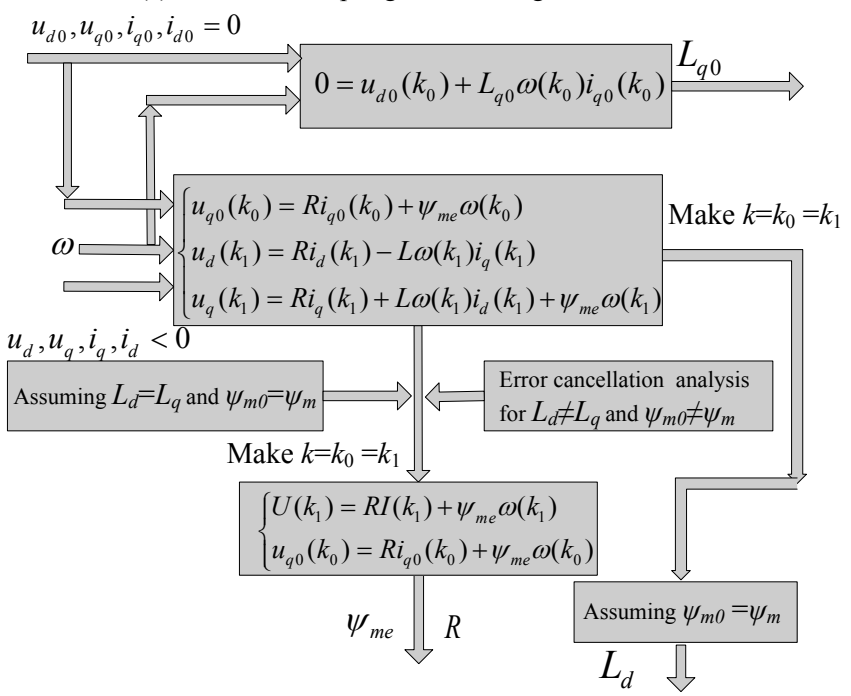

(b) Mathematical model

Fig. 4. Schematic diagrams of estimation and mathematical model.

The main features of proposed method include:

(a) Two sets of simplified PMSM state equations corresponding to $i_{d}=0$ and $i_{d} \neq 0$ are obtained by injecting a short pulse of negative $d$-axis current and solved simultaneously;

(b) The convergence of solutions will be ensured by assuming $L_{q}\left(i_{d} \neq 0\right)=L_{d}\left(i_{d} \neq 0\right)$ (due to the non-salient pole structure of used PMSM) and $\psi_{m}\left(i_{d} \neq 0\right)=\psi_{m}\left(i_{d}=0\right)$ since the corresponding simplified PMSM equations are of full rank;

(c) The error analysis is carried out and a minimum $\left|i_{d}\right|$ is determined to ensure negligible estimation errors in winding resistance and rotor flux linkage under $i_{d}=0$ control due to the assumption of $L_{q}\left(i_{d} \neq 0\right)=L_{d}\left(i_{d} \neq 0\right)$ and $\psi_{m}\left(i_{d} \neq 0\right)=\psi_{m}\left(i_{d}=0\right)$;

(d) The proposed method does not need the nominal value of any parameter.

Under normal operation, the SPMSM is under $i_{d}=0$ control. The two sets of PMSM state equations are obtained by measuring two sets of steady state rotor speed, $d q$-axis currents and voltages, Data0 and Data1, corresponding to $i_{d}=0$ and $i_{d} \neq 0$, respectively. The data associated with $i_{d}=0$, Data0, are firstly 
measured and then a short pulse (pulse width=52ms) of negative $i_{d}$ is injected, and the measurement of corresponding data (Data 1 ) is started after $2 \mathrm{~ms}$ of injection, both with the same sampling period and sampling number (N), as shown schematically in Fig. 4(a). The $2 \mathrm{~ms}$ delay before starting the measurement of Data1 is to ensure that the measurement is conducted after settling of step transients correlated to the $i_{d}$ pulse. Since the duration of injected pulse current is very short, the rotor speed and winding resistance may be assumed to be constant as the mechanical and thermal constants are usually much larger than the electrical constant. Therefore, the corresponding two sets of $d q$-axis equations are:

$u_{d 0}\left(k_{0}\right)=-L_{q 0} \omega\left(k_{0}\right) i_{q 0}\left(k_{0}\right)$

$u_{q 0}\left(k_{0}\right)=R i_{q 0}\left(k_{0}\right)+\psi_{m 0} \omega\left(k_{0}\right)$

$u_{d}\left(k_{1}\right)=R i_{d}\left(k_{1}\right)-L_{q} \omega\left(k_{1}\right) i_{q}\left(k_{1}\right)$

$u_{q}\left(k_{1}\right)=R i_{q}\left(k_{1}\right)+L_{d} \omega\left(k_{1}\right) i_{d}\left(k_{1}\right)+\psi_{m} \omega\left(k_{1}\right)$

where variables and parameters with/without suffix ' 0 ' are referred to those associated with Data0 and Data1, respectively. ' $k_{0}$ ' and ' $k_{1}$ ' are indices of the $k_{0}$-th and $k_{1}$-th measured instants for Data0 and Data1, respectively.

Firstly, assuming $L=L_{q}=L_{d}$ and $\psi_{m e}=\psi_{m}=\psi_{m 0}$, (4) can be simplified to (5):

$u_{d 0}\left(k_{0}\right)=-L_{q 0} \omega\left(k_{0}\right) i_{q 0}\left(k_{0}\right)$

$u_{q 0}\left(k_{0}\right)=R i_{q 0}\left(k_{0}\right)+\psi_{m e} \omega\left(k_{0}\right)$

$u_{d}\left(k_{1}\right)=R i_{d}\left(k_{1}\right)-L \omega\left(k_{1}\right) i_{q}\left(k_{1}\right)$

$u_{q}\left(k_{1}\right)=R i_{q}\left(k_{1}\right)+L \omega\left(k_{1}\right) i_{d}\left(k_{1}\right)+\psi_{m e} \omega\left(k_{1}\right)$

The rank of (5) is four. Hence, (5) is full rank for simultaneously solving $R, L, L_{q 0}$, and $\psi_{m e}$. The corresponding Adaline estimators based on (5) are described in Appendix A.

The estimation error caused by the above assumptions of $L=L_{q}=L_{d}$ and $\psi_{m e}=\psi_{m}=\psi_{m 0}$ is analyzed as follows and a method to minimize this error is proposed and investigated.

Let $\Delta L=L_{q}-L_{d}$ and $\Delta \psi_{m}=\psi_{m 0}-\psi_{m}$, i.e. $\Delta L=L_{q}\left(i_{d} \neq 0\right)-L_{d}\left(i_{d} \neq 0\right)$ and $\Delta \psi_{m}=\psi_{m}\left(i_{d}=0\right)-\psi_{m}\left(i_{d} \neq 0\right)$, the estimation error $\psi_{\text {merror }}$ caused by assuming $L_{q}=L_{d}$ and $\psi_{m}=\psi_{m 0}$ can be derived from (4) and (5) (derivation is given in Appendix C):

$$
\begin{aligned}
\psi_{\text {merror }} & =\psi_{m e}-\psi_{m 0} \\
& =-\frac{\Delta \psi_{m} i_{q}\left(k_{1}\right) i_{q 0}\left(k_{0}\right)+\Delta L i_{d}\left(k_{1}\right) i_{q 0}\left(k_{0}\right) i_{q}\left(k_{1}\right)}{i_{q 0}\left(k_{0}\right) i_{q}\left(k_{1}\right)-i_{q}^{2}\left(k_{1}\right)-i_{d}^{2}\left(k_{1}\right)}
\end{aligned}
$$

If the relative magnitude of $\psi_{\text {merror }}$ with reference to $\psi_{m 0}$ can be made negligible, the estimated $\psi_{m e}$ will be a good approximation to the actual $\psi_{m 0}$.

Under constant torque control, $i_{q}\left(i_{d}<0\right) \approx i_{q 0}\left(i_{d}=0\right)$. Therefore, the estimation error $\psi_{\text {merror }},(6)$, can be simplified as a monotone decreasing function of $i_{d}$ :

$\left|\psi_{\text {merror }}\right| \approx\left|\frac{\Delta \psi_{m} i_{q}^{2}\left(k_{1}\right)}{i_{d}^{2}\left(k_{1}\right)}+\frac{\Delta L i_{q}^{2}\left(k_{1}\right)}{i_{d}\left(k_{1}\right)}\right|$

Therefore, irrespective of values of $\Delta L$ and $\Delta \psi_{m}, \psi_{\text {merror }}$ can be minimized as long as $\left|i_{d}\right|$ is large enough.

By way of example, Fig. 5 shows the variation of normalized $\psi_{\text {merror }}$, with reference to $\psi_{m 0}$, with the injected $d$-axis current for various $\Delta L$ and $\Delta \psi_{m}$. Although it is difficult to obtain $\Delta L$ and $\Delta \psi_{m}$ in practice, $\psi_{\text {merror }}$ may also be measured by the following approximation method:

a. Measure the winding resistance at standstill.

b. Using the measured winding resistance at standstill, start the PMSM and obtain the rotor flux linkage $\psi_{m 0}(78.4 \mathrm{mWb})$ at $i_{d}=0$ by the Scheme II in section II.

c. Obtain $\psi_{m e}$ from the proposed method using (A.10).

d. $\psi_{\text {merror }}=\psi_{m e}-\psi_{m 0}$

Fig.6 shows the corresponding measured variation of normalized $\psi_{\text {merror }}$, with reference to $\psi_{m 0}$, with the injected $d$-axis current. As can be seen from (7) and Figs.5 and 6, $\psi_{\text {merror }}$ reduces with the amplitude of $i_{d}$. However, it is preferable to employ a negative pulse of $i_{d}$ since it leads to smaller estimation errors due to error cancellation (note: $\Delta \psi_{m}>0$ and for majority PMSM machines $\Delta L>0$ ). Of course, in this case, it is important to ensure that there will be no irreversible demagnetization of permanent magnets. This paper employs a negative pulse of $i_{d}$ $=-2 \mathrm{~A}$ in the experiments, the percentage of the injected $i_{d}$ to the rated current being $50 \%$.

\section{EXPERIMENTAL RESUlts OF PROPOSED METHOD AND INVESTIGATION}

\section{A. Experimental Results}

The employed DSP based SPMSM vector control system and prototype machine are identical to those used in section II, details being given in Appendix B. The injected short pulse $d$-axis current $\left(i_{d}=-2 \mathrm{~A}\right)$ and other sampled signals for estimation are shown in Fig. 7, which have been filtered by first-order Butterworth low-pass filters. The estimation results obtained by the proposed method are shown in Fig. 8. It is evident that the convergence speed of Adaline estimator is so fast that the pulse width of injected $i_{d}$ can be chosen to be less than $50 \mathrm{~ms}$. In addition, even if the Adaline estimator cannot entirely converge to the final value in $50 \mathrm{~ms}$, the memorized Data0 and Data1 can be used to calculate iteratively until it converges to the final value in the host computer. Therefore, the following estimations are all based on this iterative online estimation and the pulse width of injected $i_{d}$ is $50 \mathrm{~ms}$. As can be seen from Fig.7, the influence of injecting a short pulse of $i_{d}$ on output torque and speed is negligible due to mechanical inertia and fast response of current loop PI controller.

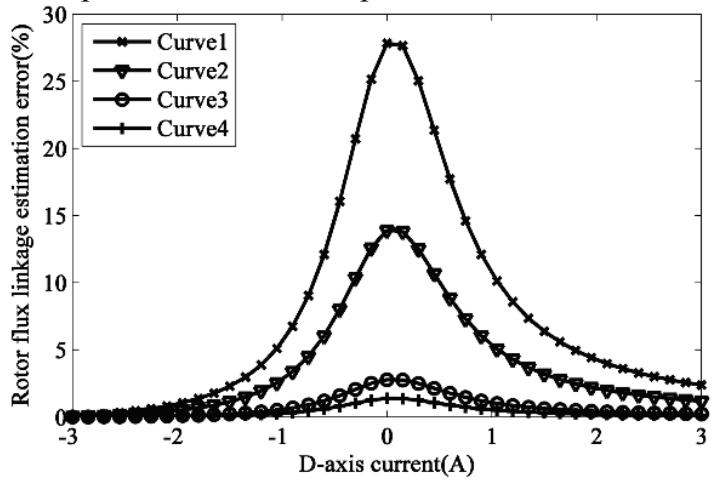

Fig. 5. Calculated variation of $\left|\psi_{\text {merror }} / \psi_{m 0}\left(T_{0}\right)\right|$ with $i_{d}$ under various $\Delta L$ and $\Delta \psi_{m} . i_{q}=3.46 \mathrm{~A}, i_{q 0}=3.34 \mathrm{~A}, \psi_{m 0}\left(T_{0}\right)=77.6 \mathrm{mWb}, L_{d}=3.24 \mathrm{mH}$. Curve1: $\Delta \psi_{m}=1 \%$ $\psi_{m 0}, \Delta L=10 \% L_{d}$. Curve2: $\Delta \psi_{m}=0.5 \% \psi_{m 0}, \Delta L=5 \% L_{d}$. Curve3: $\Delta \psi_{m}=0.1 \% \psi_{m 0}$, $\Delta L=1 \% L_{d}$. Curve $4: \Delta \psi_{m}=0.05 \% \psi_{m 0}, \Delta L=0.5 \% L_{d}$. 


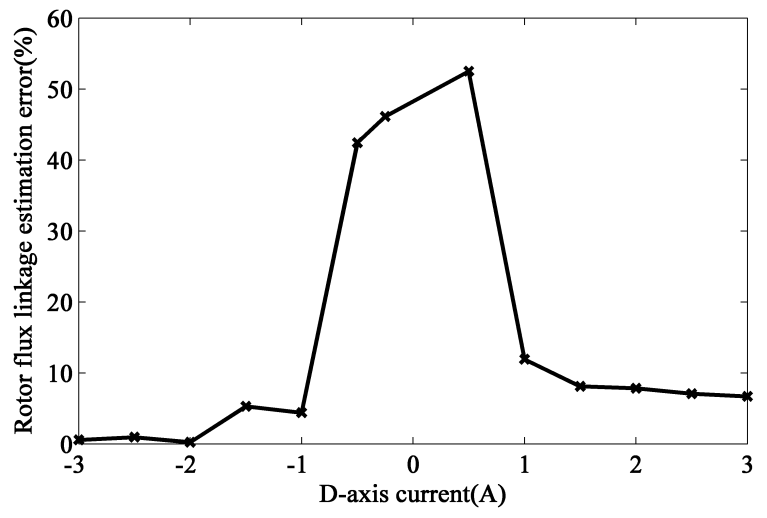

Fig. 6. Measured variation of $\left|\psi_{\text {merror }} / \psi_{m 0}\left(T_{0}\right)\right|$ with $i_{d}$.
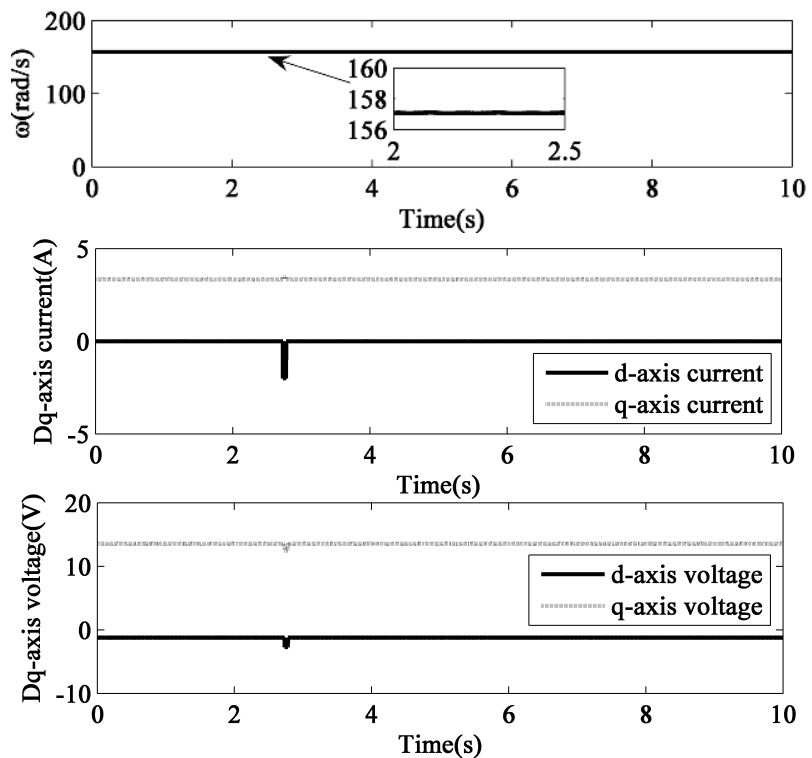

Fig. 7. Sampled electrical angular speed, $d q$-axis currents, voltages, and injected current pulse $\left(i_{d}=-2 \mathrm{~A}\right)$.

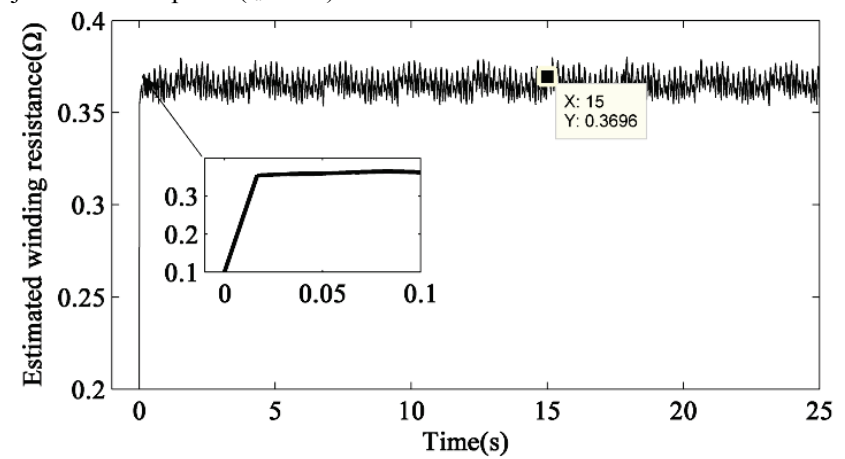

(a) Estimated winding resistance

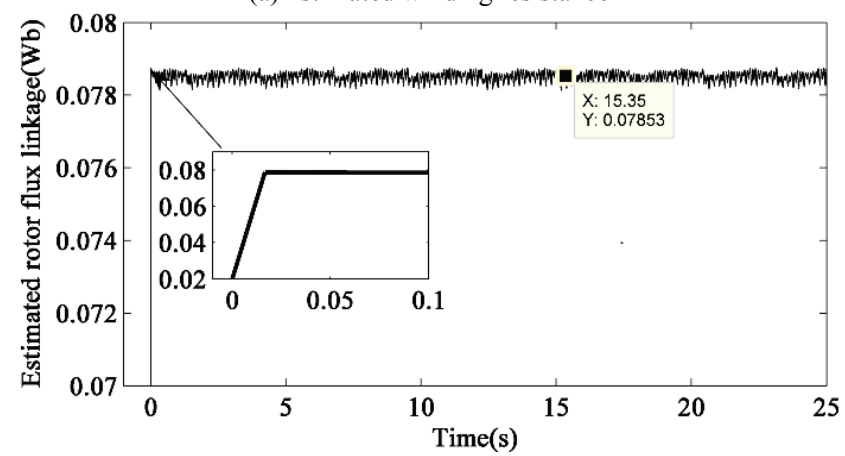

(b) Estimated rotor flux linkage

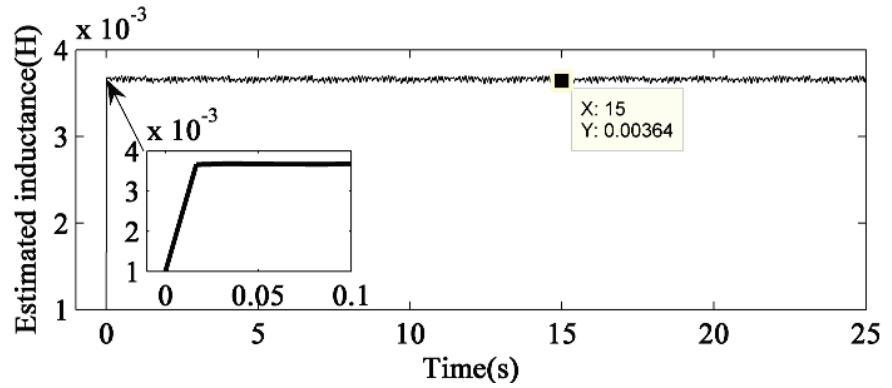

(c) Estimated $d$-axis inductance

Fig. 8. Estimated parameters by proposed method (injected $i_{d}=-2 \mathrm{~A}$ ).

As can be seen from Figs. 8(a) and (b), the estimated winding resistance $(0.370 \Omega)$ is almost the same as the measured resistance $(0.373 \Omega), \quad \psi_{\text {merror }}=\psi_{m e}-\psi_{m 0} \approx 78.5-78.4=0.1 \mathrm{mWb}$. The relative error $\psi_{\text {merror }} / \psi_{m 0}$ is only $0.13 \%$. Therefore, the estimation results are of high accuracy.

\section{B. Step Change in Winding Resistance Value}

In order to verify the effectiveness of proposed method, a step change in winding resistance value is applied to verify the accurate tracking ability of proposed method. Three resistances $\left(R_{\mathrm{p}}=0.414 \Omega\right)$ are simultaneously connected in series with three-phase windings. The estimated results are shown in Fig. 9 and Table I.

As can be seen from Table I, $\psi_{m p}$ and $L_{d p}$ are estimated rotor flux linkage and $d$-axis inductance after adding $R_{\mathrm{p}}$. The estimated $R+R_{\mathrm{p}}(0.792 \Omega)$ is quite close to the actual resistance $(0.787 \Omega)$. From (4b), there are two parameters in (4b) and the rotor flux linkage can be accurately estimated if the winding resistance is accurately estimated when $i_{d}=0$. As the experiment result shows that the estimated winding resistance is of high accuracy, it is convincing that the estimated rotor flux linkage by (A.11) is accurate. Therefore, the proposed method has high performance in accurately tracking the variation of parameters. TABLE I

COMPARISON OF ESTIMATED STEADY-STATE PARAMETERS

\begin{tabular}{ccc}
\hline Parameters & Nominal Values & Estimated Values \\
$R$ & $0.373 \Omega$ & $0.370 \Omega$ \\
$R+R_{\mathrm{p}}$ & $0.787 \Omega$ & $0.792 \Omega$ \\
$\Psi_{m}$ & $77.6 \mathrm{mWb}$ & $78.6 \mathrm{mWb}$ \\
$\Psi_{m p}$ & $77.6 \mathrm{mWb}$ & $78.0 \mathrm{mWb}$ \\
$L_{d}$ & $3.24 \mathrm{mH}$ & $3.68 \mathrm{mH}$ \\
$L_{d p}$ & $3.24 \mathrm{mH}$ & $3.65 \mathrm{mH}$ \\
\hline
\end{tabular}

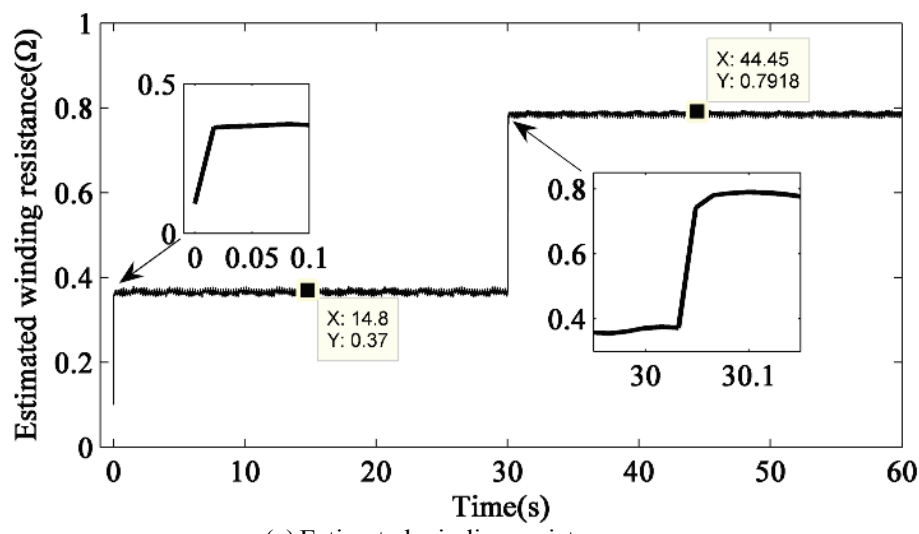

(a) Estimated winding resistance 


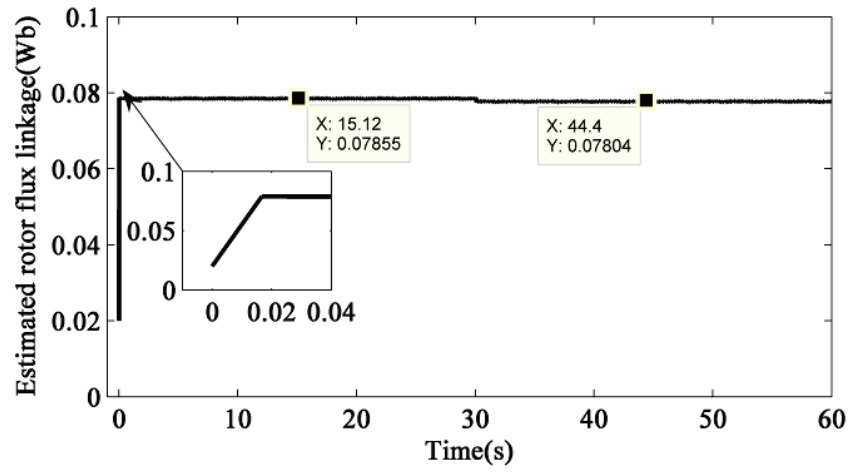

(b)Estimated rotor flux linkage

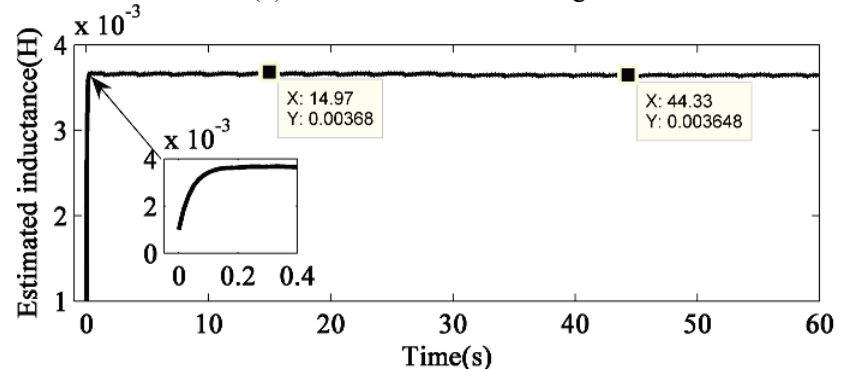

(c) Estimated $d$-axis inductance

Fig. 9. Estimated parameters with a step change in winding resistance value (injected $i_{d}=-2 \mathrm{~A}$ ).

\section{Temperature Variation in SPMSM}

A heater is used to heat the prototype SPMSM. The heating experiments are divided into three steps:

a. Estimate the winding resistance, rotor flux linkage and inductance at the beginning $\left(\mathrm{t}=0, T=T_{0}\right)$.

b. Keep on heating the PMSM for 20 minutes and estimate the winding resistance, rotor flux linkage and inductance $(t=20$ minutes).

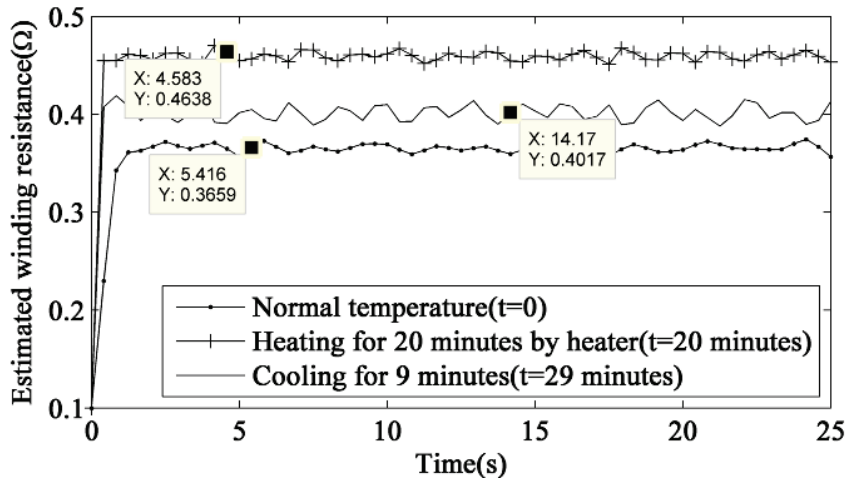

(a) Estimated winding resistance

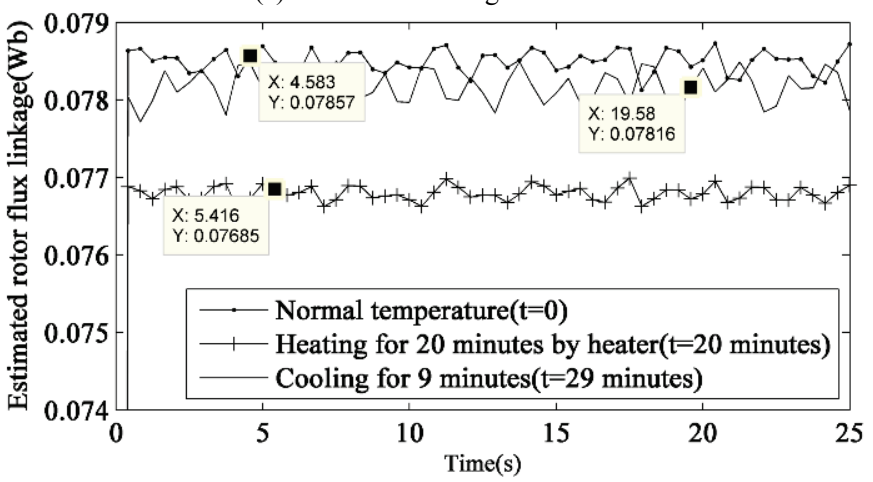

(b) Estimated rotor flux linkage

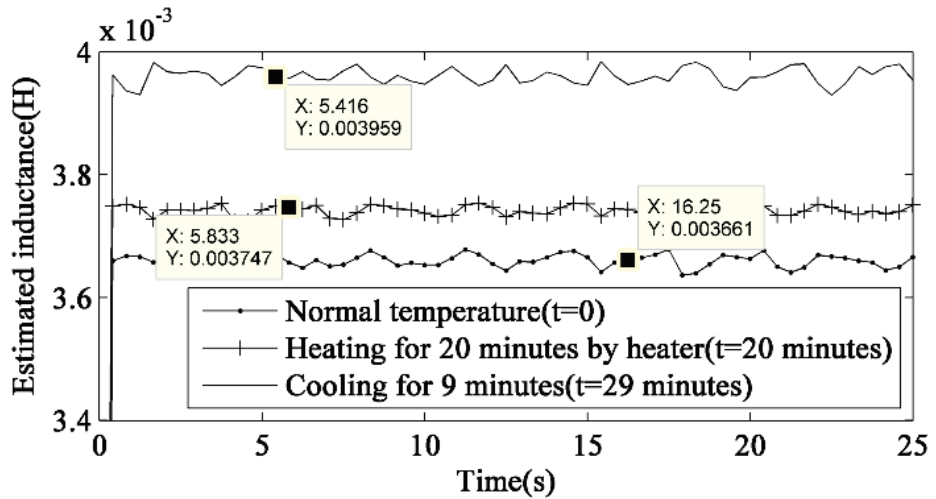

(c) Estimated $d$-axis inductance

Fig. 10. Estimated parameters with temperature variation (injected $i_{d}=-2 \mathrm{~A}$ ).

c. Switch off the power source of heater and PMSM for naturally cooling. The PMSM is restarted after 9 minutes' cooling and the parameters are estimated ( $\mathrm{t}=29$ minutes).

The estimation results are shown in Fig. 10. As can be seen from Fig. 10(a), the winding resistance will vary from $0.366 \Omega$ to $0.464 \Omega$ after 20 minutes heating, and drop to $0.402 \Omega$ after 9 minutes cooling. The rotor flux linkage will vary from $78.6 \mathrm{mWb}$ to $76.9 \mathrm{mWb}$ after 20 minutes heating, and rise to $78.2 \mathrm{mWb}$ after 9 minutes cooling, Fig. 10(b). In addition, as can be seen from Fig. 10(c), the estimated value of $d$-axis inductance $L_{d}$ will vary with temperature, which is mainly caused by $\Delta \psi_{m}$ in designing (A.13). Since the estimation of $R$, $L_{q 0}$ and $\psi_{m 0}$ is independent of estimating $L_{d}$, the variation in estimated $L_{d}$ will not affect their estimation accuracy.

\section{CONCLUSIONS}

The ill-convergence in PMSM multi-parameter estimation is investigated and it is verified that the PMSM model in multi-parameter estimation under $i_{d}=0$ control is rank-deficient for simultaneously estimating winding resistance and rotor flux linkage and cannot ensure them to converge to correct parameter values, although it is full rank for estimating $q$-axis inductance when $i_{d}=0$. Therefore, a new method is proposed based on injecting a short pulse of negative $i_{d}$ current and simultaneously solving two sets of simplified non-salient pole PMSM state equations corresponding to $i_{d}=0$ and $i_{d} \neq 0$. The convergence of solutions is ensured and the minimum $\left|i_{d}\right|$ is determined from the error analysis. It has been verified by experiments with good performance. It does not need the nominal value of any parameters and can make the estimated winding resistance and rotor flux linkage converge to the actual values. In addition, the proposed method has negligible influence on the output torque and rotor speed. The proposed error analysis method is applicable for non-salient pole PMSM and the design for simultaneously estimating winding resistance, rotor flux linkage, $L_{d}$ and $L_{q}$ of interior PMSM which has significant saliency is being investigated and the findings will be published in the future.

\section{Appendix A - Design Estimators by Adaline NN}

Since Adaline NN algorithm [26] requires less computation and is faster to converge compared with algorithms such as MRAS 
and EKF, it is described in this appendix and used to design all the estimators throughout the paper.

\section{A. Structure of Adaline NN}

The mathematical model of Adaline NN can be shown as follows:

$$
O\left(W_{i}, X_{i}\right)=\sum_{i=0}^{n} W_{i} X_{i}
$$

where $W_{i}$ is the net weight and $X_{i}$ is the input signal. The activation function $O\left(W_{i}, X_{i}\right)$ of the network output node is a linear function.

The structure of Adaline NN [26] is shown in Fig. 11.

In this paper, the PMSM is regarded as a reference model and the Adaline NN will follow the variation of PMSM parameters. The network is composed of different single node subnets while winding resistance, inductance and flux linkage are regarded as the weights of these proposed subnets, respectively. $u_{d}$ and $u_{q}$ are the outputs of PMSM and will be compared with the output voltages from the Adaline model. The error caused by the output difference between the two models will be fed back to adjust the Adaline NN weights by using the least mean square learning method (LMS [26]). As can be seen from (A.1) and Fig. 11 , if $d(k)$ is the sampled target output, the weight adjustment can be obtained via LMS:

$W_{i}(k+1)=W_{i}(k)+2 \eta X_{i}(d(k)-O)$

In (A.2), $\eta$ is the convergence factor which adjusts the weight convergence speed. If the parameter to be estimated can be mathematically expressed in the form of general Adaline NN structure, as shown in Fig. 11, its estimator can be directly derived from (A.2) by comparing its net structure with the general Adaline NN structure.

\section{B. Adaline Estimators for Schemes I-IV}

Fig. 12(a) shows the complete estimation system for Scheme I-IV and the NN structures will be changed in different schemes. The subnet structures of inductance, resistance and rotor flux linkage estimators used in Schemes I-IV are shown in Figs. 12(b)-(d), respectively. As can be seen from (3), $L_{q}$ can be regarded as the weight of a single node subnet while $-u_{d}(k)$ and $\omega(k) i_{q}(k)$ are regarded as the net output and input, respectively. Therefore, the iterative training algorithm of $q$-axis inductance can be obtained by the LMS. From Fig. 12(b), assuming $X_{i}=\omega(k) i_{q}(k), O=-\hat{u}_{d}(k)$ and $d(k)=-u_{d}(k)$, the training algorithm of $q$-axis inductance can be expressed as:

$$
\hat{L}_{q}(k+1)=\hat{L}_{q}(k)+2 \eta \omega(k) i_{q}(k)\left(\hat{u}_{d}(k)-u_{d}(k)\right)
$$

The same design principle can be applied to the $q$-axis equation to obtain the training algorithms for estimating resistance and rotor flux linkage. From Figs. 12(c), assuming $X_{i}=i_{q}(k)$, $O=\hat{u}_{q}(k)-\psi_{m} \omega(k)$ and $d(k)=u_{q}(k)-\psi_{m} \omega(k)$, the training algorithm of resistance can be expressed as:

$$
\hat{R}(k+1)=\hat{R}(k)+2 \eta i_{q}(k)\left(u_{q}(k)-\hat{u}_{q}(k)\right)
$$

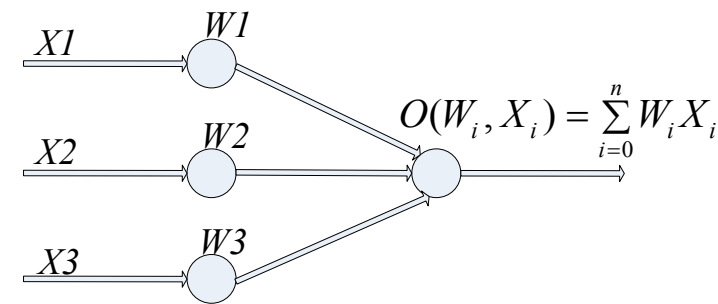

Fig. 11. Structure of an Adaline NN

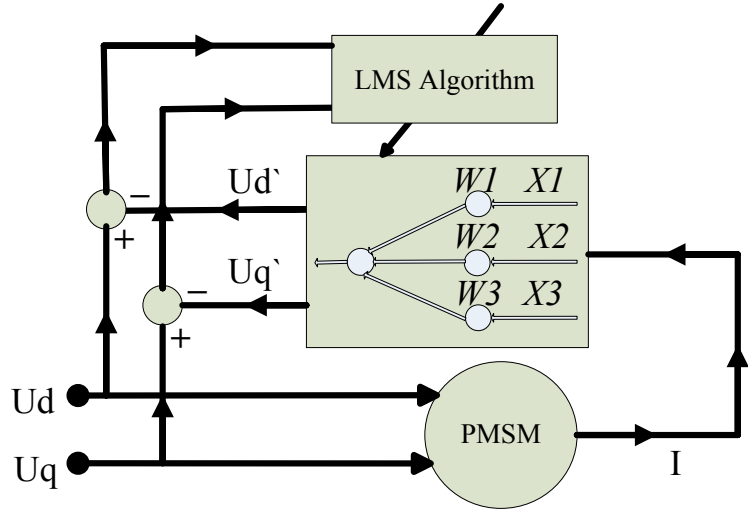

(a) Complete estimation system

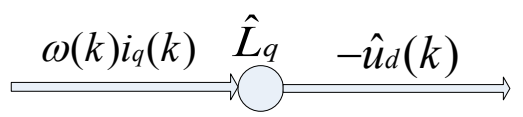

(b) Subnet of $q$-axis inductance estimator

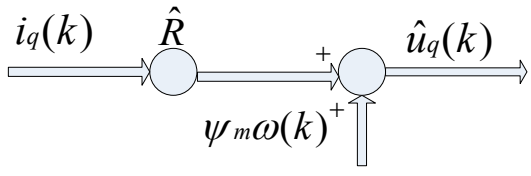

(c) Subnet of winding resistance estimator

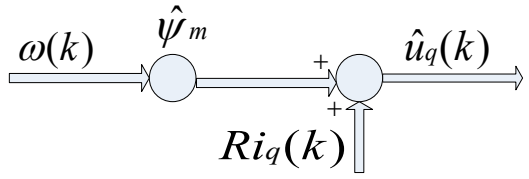

(d) Subnet of rotor flux linkage estimator

Fig. 12. Adaline NN based PMSM parameter estimation and structure of subnets $\left(i_{d}=0\right)$.

Similarly, from Fig. 12(d), assuming $X_{i}=\omega(k), O=\hat{u}_{q}(k)$ - $R i_{q}(k)$ and $d(k)=u_{q}(k)-R i_{q}(k)$, the training algorithm of rotor flux linkage can be expressed as:

$\hat{\psi}_{m}(k+1)=\hat{\psi}_{m}(k)+2 \eta \omega(k)\left(u_{q}(k)-\hat{u}_{q}(k)\right)$

When $i_{d} \neq 0$, similar to (A.4), the winding resistance can also be obtained from (2a) by assuming $O=\hat{u}_{d}(k)+L_{q} \omega(k) i_{q}(k)$, $X_{i}=i_{d}(k)$ and $d(k)=u_{d}(k)+L_{q} \omega(k) i_{q}(k)$ and can be expressed as:

$\hat{R}(k+1)=\hat{R}(k)+2 \eta i_{d}(k)\left(u_{d}(k)-\hat{u}_{d}(k)\right)$

\section{Adaline Estimators based on (5)}

The estimation will be started after the completion of measuring and memorizing Data 0 and Data 1 . As can be seen from Fig. 13, since Data0 and Data1 are memorized in RAM, the numbering can be reset to be $k=k_{0}=k_{1}=0$ at the beginning of estimation and the memorized two sets of data are simultaneously sent to the proposed estimation method for 
iterative computation from 0 to $\mathrm{N}-1$ in sequence. Therefore, $k_{0}$ will be kept always equal to $k_{1}$ in the whole estimation processes and $k=k_{0}=k_{1}$ will be kept for the convenience of following estimator design.

From (5), (5c) $\frac{i_{d}\left(k_{1}\right)}{i_{q}\left(k_{1}\right)}+(5 d)$ becomes

$u_{d}\left(k_{1}\right) \frac{i_{d}\left(k_{1}\right)}{i_{q}\left(k_{1}\right)}+u_{q}\left(k_{1}\right)=R\left(i_{q}\left(k_{1}\right)+\frac{i_{d}^{2}\left(k_{1}\right)}{i_{q}\left(k_{1}\right)}\right)+\psi_{m e} \omega\left(k_{1}\right)$

Let $U\left(k_{1}\right)=u_{d}\left(k_{1}\right) \frac{i_{d}\left(k_{1}\right)}{i_{q}\left(k_{1}\right)}+u_{q}\left(k_{1}\right)$ and $I\left(k_{1}\right)=i_{q}\left(k_{1}\right)+\frac{i_{d}^{2}\left(k_{1}\right)}{i_{q}\left(k_{1}\right)}$,

Combining (5b) and (A.7), equation (A.8) is obtained. Its rank is 2 . Therefore, (A.8) can be used for simultaneously estimating winding resistance and rotor flux linkage:

$\left\{\begin{array}{l}U\left(k_{1}\right)=R I\left(k_{1}\right)+\psi_{m e} \omega\left(k_{1}\right) \\ u_{q 0}\left(k_{0}\right)=R i_{q 0}\left(k_{0}\right)+\psi_{m e} \omega\left(k_{0}\right)\end{array}\right.$

Thus, $u_{q 0}\left(k_{0}\right)-U\left(k_{1}\right)=R\left(i_{q 0}\left(k_{0}\right)-I\left(k_{1}\right)\right)$

Based on (A.9), the subnet structure of winding resistance estimator is shown in Fig. 14(a), which shows the input and output of the estimator. Assuming $X_{i}=i_{q 0}\left(k_{0}\right)-I\left(k_{1}\right), O=$ $\hat{u}_{q 0}\left(k_{0}\right)-\hat{U}\left(k_{1}\right)$ and $d(k)=u_{q 0}\left(k_{0}\right)-U\left(k_{1}\right)$, the Adaline winding resistance estimator can be expressed as:

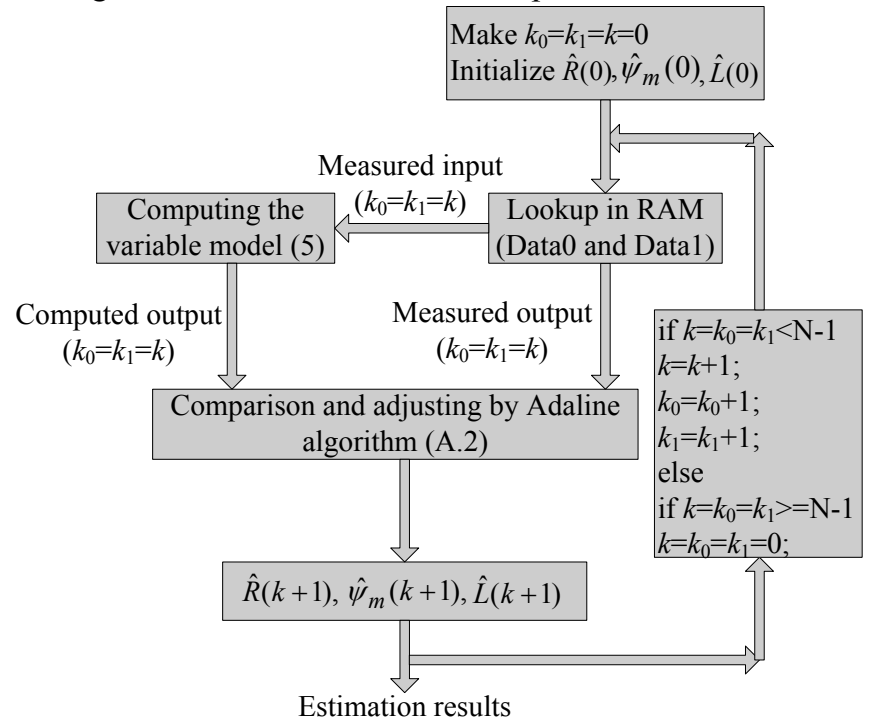

Fig. 13. Iterative computation processes of proposed Adaline $\mathrm{NN}$ based estimation strategy.

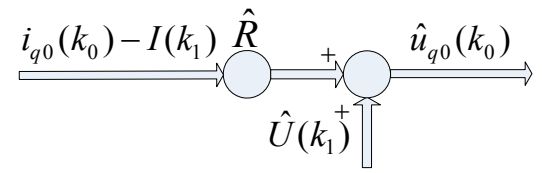

(a) Subnet of winding resistance estimator

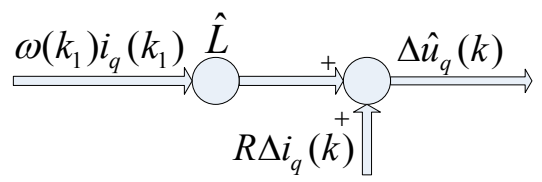

(b) Subnet of $d$-axis inductance estimator

Fig. 14. Subnet structures of proposed Adaline estimation.
$\hat{R}(k+1)=\hat{R}(k)+$

$2 \eta\left(i_{q 0}\left(k_{0}\right)-I\left(k_{1}\right)\right)\left(u_{q 0}\left(k_{0}\right)-U\left(k_{1}\right)-\hat{u}_{q 0}\left(k_{0}\right)+\hat{U}\left(k_{1}\right)\right)$

where $\hat{U}$ and $\hat{u}_{q 0}$ are output voltages of variable model and $k=k_{0}=k_{1}$. With the estimated winding resistance value from (A.10), the estimator proposed in Fig. 12(d) can be used for estimating rotor flux linkage, whose subnet structure shows the input and output of the estimator. Therefore, assuming $X_{i}=\omega\left(k_{0}\right), O=\hat{u}_{q_{0}}\left(k_{0}\right)-R i_{q_{0}}\left(k_{0}\right)$ and $d(k)=u_{q_{0}}\left(k_{0}\right)-$ $R i_{q_{0}}\left(k_{0}\right)$, the Adaline rotor flux linkage estimator can be obtained from (5b) and is shown as follows:

$\hat{\psi}_{m e}(k+1)=\hat{\psi}_{m e}(k)+2 \eta \omega\left(k_{0}\right)\left(u_{q 0}\left(k_{0}\right)-\hat{u}_{q 0}\left(k_{0}\right)\right)$

where $\hat{u}_{q 0}$ is the output of variable model and $k=k_{0}=k_{1}$. Since the $q$-axis inductance can be individually estimated from (5a), the estimator proposed in Fig. 12(b) can be used for estimating $q$-axis inductance, whose subnet structure shows the input and output of the estimator. Assuming $X_{i}=\omega\left(k_{0}\right) i_{q 0}\left(k_{0}\right)$, $O=-\hat{u}_{d 0}\left(k_{0}\right)$ and $d(k)=-u_{d 0}\left(k_{0}\right), q$-axis inductance $\left(L_{q 0}=\right.$ $\left.L_{q}\left(i_{d}=0\right)\right)$ can be estimated from (5a):

$\hat{L}_{q 0}(k+1)=\hat{L}_{q 0}(k)+2 \eta \omega\left(k_{0}\right) i_{q 0}\left(k_{0}\right)\left(\hat{u}_{d 0}\left(k_{0}\right)-u_{d 0}\left(k_{0}\right)\right)$

where $\hat{u}_{d 0}$ is the output of variable model and $k=k_{0}=k_{1}$. With the estimated winding resistance, the $d$-axis inductance estimator can be obtained from (5d) and (5b). (5d) $-(5 \mathrm{~b})$ becomes:

$\Delta u_{q}(k)=R \Delta i_{q}(k)+L \omega\left(k_{1}\right) i_{d}\left(k_{1}\right)$

where $\Delta u_{q}(k)=u_{q}\left(k_{1}\right)-u_{q 0}\left(k_{0}\right), \Delta i_{q}(k)=i_{q}\left(k_{1}\right)-i_{q 0}\left(k_{0}\right)$ and $k=k_{0}=k_{1}$. Based on the equation (5d)-(5b), the subnet structure of $d$-axis inductance estimator is shown in Fig. 14(b), which shows the input and output of the estimator. Therefore, assuming $X_{i}=\omega\left(k_{1}\right) i_{d}\left(k_{1}\right), O=\Delta \hat{u}_{q}(k)-R \Delta i_{q}(k)$ and $d(k)=$ $\Delta u_{q}(k)-R \Delta i_{q}(k), L_{d}(=L)$ can be estimated by:

$\hat{L}_{d}(k+1)=\hat{L}_{d}(k)+2 \eta \omega\left(k_{1}\right) i_{d}\left(k_{1}\right)\left(\Delta u_{q}(k)-\Delta \hat{u}_{q}(k)\right)$

However, as can be seen from (4d)-(4b):

$\Delta u_{q}(k)=R \Delta i_{q}(k)+L_{d} \omega\left(k_{1}\right) i_{d}\left(k_{1}\right)-\Delta \psi_{m} \omega\left(k_{1}\right)$

where $\Delta \psi_{m}=\psi_{m 0}-\psi_{m} \neq 0$. Hence, it will cause error in the estimated $d$-axis inductance due to temperature variation.

\section{Appendix B - Test Rig and Prototype SPMSM}

The schematic diagram and hardware platform of the DSP (TMS TI 2812) based vector control system are shown in Figs. 15 and 16 . The design parameters of prototype machine are shown in Table II. The waveforms of measured stator currents, voltages and electrical angular speed are shown in Fig. 17. The current signals are obtained from the Hall transducers and then sampled by the DSP ADC. The DC link is connected with the DC power source whose output is fixed to $36 \mathrm{~V}$. The method proposed in [25] is used for compensating the inverter. 


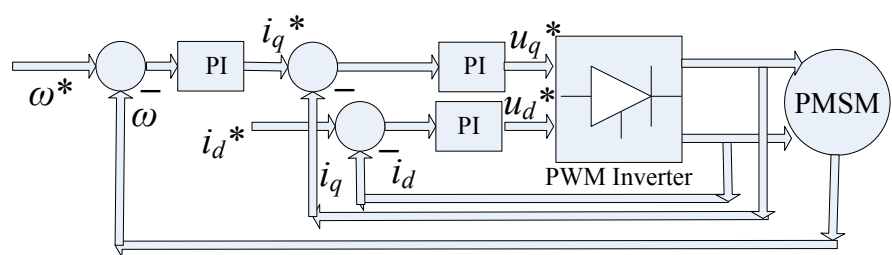

Fig. 15. Schematic of vector controlled PMSM drive system.

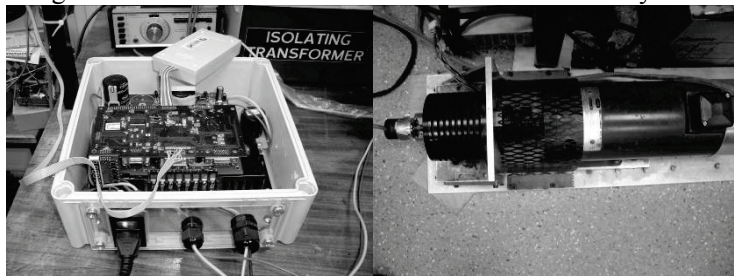

Fig. 16. DSP platform and experimental test rig.
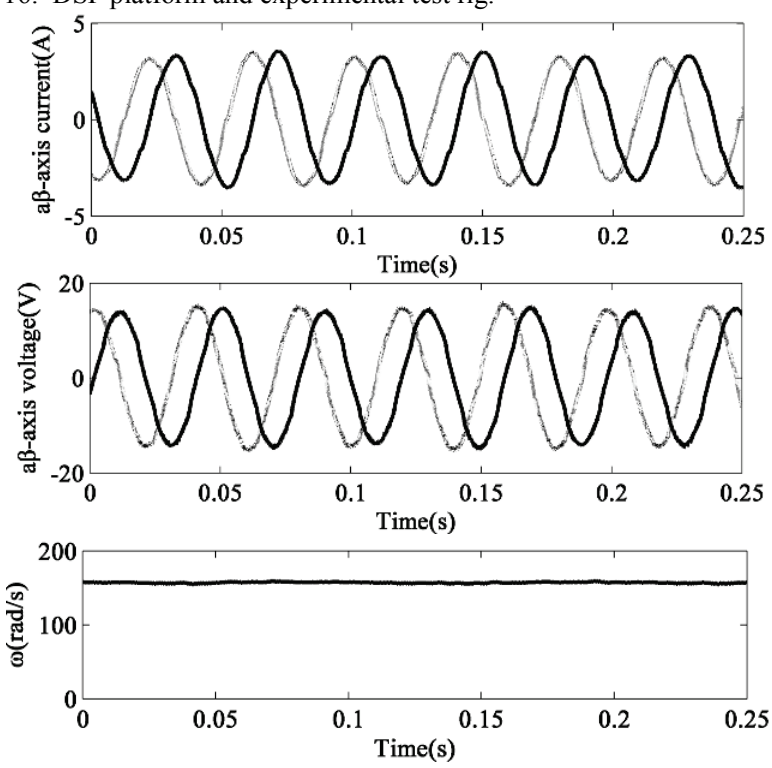

Fig. 17. Typical waveforms of sampled PMSM signals.

TABLE II

DESIGN PARAMETERS AND SPECIFICATION OF PMSM

\begin{tabular}{ll}
\hline Rated current & $4 \mathrm{~A}$ \\
Rated speed & $400 \mathrm{rpm}$ \\
DC link voltage & $36 \mathrm{~V}$ \\
Nominal phase resistance $\left(T=25^{\circ} \mathrm{C}\right)$ & $0.330 \Omega$ \\
Nominal terminal wire resistance & $0.043 \Omega$ \\
Nominal self inductance & $2.91 \mathrm{mH}$ \\
Nominal mutual inductance & $-0.330 \mathrm{mH}$ \\
Nominal $d$-axis inductance & $3.24 \mathrm{mH}$ \\
Nominal $q$-axis inductance & $3.24 \mathrm{mH}$ \\
Nominal amplitude of flux induced by magnets & $77.6 \mathrm{mWb}$ \\
Inertia & $0.8 \mathrm{e}-5 \mathrm{kgm}^{2}$ \\
Number of pole pairs & 5 \\
\hline
\end{tabular}

Note: Nominal values are measured.

Appendix C - Expressions of $\psi_{m 0}$ and $\psi_{m e}$ Used in Proposed Method

Combining (4c) $\frac{i_{d}\left(k_{1}\right)}{i_{q}\left(k_{1}\right)}+(4 d)$ and (4b), it becomes:

$\left\{\begin{array}{l}U\left(k_{1}\right)=R I\left(k_{1}\right)+\left(\psi_{m 0}-\Delta \psi_{m}\right) \omega\left(k_{1}\right)-\Delta L \omega\left(k_{1}\right) i_{d}\left(k_{1}\right) \\ u_{q 0}\left(k_{0}\right)=R i_{q 0}\left(k_{0}\right)+\psi_{m 0} \omega\left(k_{0}\right)\end{array}\right.$

where $U\left(k_{1}\right)=u_{d}\left(k_{1}\right) \frac{i_{d}\left(k_{1}\right)}{i_{q}\left(k_{1}\right)}+u_{q}\left(k_{1}\right), \quad I\left(k_{1}\right)=i_{q}\left(k_{1}\right)+\frac{i_{d}^{2}\left(k_{1}\right)}{i_{q}\left(k_{1}\right)}$.
From (C.1), since $\omega\left(k_{0}\right)=\omega\left(k_{1}\right)$ is constant, $\psi_{m 0}$ can be obtained:

$$
\begin{aligned}
\psi_{m 0}= & \frac{U\left(k_{1}\right) i_{q 0}\left(k_{0}\right)-u_{q 0}\left(k_{0}\right) I\left(k_{1}\right)}{\left(i_{q 0}\left(k_{0}\right)-I\left(k_{1}\right)\right) \omega\left(k_{0}\right)} \\
& +\frac{\Delta \psi_{m} \omega\left(k_{1}\right) i_{q 0}\left(k_{0}\right)+\Delta L \omega\left(k_{1}\right) i_{d}\left(k_{1}\right) i_{q 0}\left(k_{0}\right)}{\left(i_{q 0}\left(k_{0}\right)-I\left(k_{1}\right)\right) \omega\left(k_{0}\right)}
\end{aligned}
$$

Combining $(5 c) \frac{i_{d}\left(k_{1}\right)}{i_{q}\left(k_{1}\right)}+(5 d)$ and $(5 \mathrm{~b})$, it becomes:

$\left\{\begin{array}{l}U\left(k_{1}\right)=R I\left(k_{1}\right)+\psi_{m e} \omega\left(k_{1}\right) \\ u_{q 0}\left(k_{0}\right)=R i_{q 0}\left(k_{0}\right)+\psi_{m e} \omega\left(k_{0}\right)\end{array}\right.$

From (C.3), since $\omega\left(k_{0}\right)=\omega\left(k_{1}\right)$ is constant, $\psi_{\text {me }}$ can be obtained:

$$
\psi_{m e}=\frac{U\left(k_{1}\right) i_{q 0}\left(k_{0}\right)-u_{q 0}\left(k_{0}\right) I\left(k_{1}\right)}{\left(i_{q 0}\left(k_{0}\right)-I\left(k_{1}\right)\right) \omega\left(k_{0}\right)}
$$

\section{REFERENCES}

[1] L. Liu, and D.A. Cartes, "Synchronisation based adaptive parameter identification for permanent magnet synchronous motors," IET Control Theory \& Applicat., vol. 1, no. 4, pp. 1015-1022, Jul., 2007.

[2] B. N. Mobarakeh, F. Meibody-Tabar, and F.M. Sargos, "Mechanical sensorless control of PMSM with online estimation of stator resistance," IEEE Trans. Ind. Applicat., vol. 40, no. 2, pp. 457-471, Mar.-Apr., 2004.

[3] S. Moreau, R. Kahoul, and J-P. Louis, "Parameters estimation of permanent magnet synchronous machine without adding extra-signal as input excitation," in Proc. IEEE International Symposium on Ind. Electron., 2004, vol. 1, pp. 371-376.

[4] S. Ichikawa, M. Tomita, S. Doki, and S. Okuma, "Sensorless control of permanent-magnet synchronous motors using online parameter identification based on system identification theory," IEEE Trans. Ind. Electron., vol. 53, no. 2, pp. 363-372, Apr., 2006.

[5] M. Rashed, P.F.A. Macconnell, A.F. Stronach, and P. Acarnley, "Sensorless indirect-rotor-field-orientation speed control of a permanent-magnet synchronous motor with stator-resistance estimation," IEEE Trans. Ind. Electron., vol. 54, no. 3, pp. 1664-1675,Jun., 2007.

[6] Z.Q. Zhu, X. Zhu, and P.D. Sun, "Estimation of winding resistance and PM flux-linkage in brushless AC machines by reduced-order extended Kalman Filter," in Proc. 2007 IEEE International Conf. on Networking, Sensing and Control, 2007, pp. 740-745.

[7] T. Senjyu, Y. Kuwae, N. Urasaki and K. Uezato, "Accurate parameter measurement for high speed permanent magnet," in Proc. IEEE Power Electron. Specialists Conf., 2001, vol. 2, pp. 772-777.

[8] S. Weisgerber, A. Proca, and A. Keyhani, "Estimation of permanent magnet motor parameters," in Proc. IEEE Ind. Applicat. Society Annual Meeting, 1997, vol. 1, pp.29-34.

[9] F. Khatounian, S. Moreau, E. Monmasson, A. Janot, and F. Louveau, "Parameters Estimation of the Actuator used in Haptic Interfaces: Comparison of two Identification Methods," in Proc. IEEE International Symposium on Indust. Electron., 2006, vol. 1, pp. 211-216.

[10] W. Liu, L. Liu, and D.A. Cartes, "Particle swarm optimization as a general design tool in power engineering," in Proc. IEEE Power and Energy Society General Meeting-Conversion and Delivery of Electrical Energy in the 21st Century, 2008, pp. 1-8.

[11] K.M. Rahman, and S. Hiti, "Identification of machine parameters of a synchronous motor," IEEE Trans. Ind. Applicat., vol. 41, no. 2, pp. 557-565, Mar.-Apr., 2005.

[12] T.L. Vandoorn, F.M.D. Belie, T.J. Vyncke, J.A. Melkebeek, and P. Lataire, "Generation of multisinusoidal test signals for the identification of synchronous-machine parameters by using a voltage-source inverter," IEEE Trans. Ind. Electron., vol. 57, no. 1, pp. 430-439, Jan. 2010.

[13] Z. Gmyrek, A. Boglietti, and A. Cavagnino, "Estimation of iron losses in induction motors: calculation method, results, and analysis," IEEE Trans. Ind. Electron., vol. 57, no. 1, pp. 161-171, Jan. 2010. 
[14] S. Morimoto, M. Sanada, and Y. Yakeda, "Mechanical sensorless drives of IPMSM with online parameter identification," IEEE Trans. Ind. Applicat., vol. 42, no. 5, pp. 1241-1248, Sept.-Oct, 2006.

[15] T. Senjyu, K. Kinjo, N. Urasaki, and K. Uezato, "Parameter measurement for PMSM using adaptive identification," in Proc. IEEE International Symposium on Ind. Electron., May, 2002, vol. 3, pp. 711-716.

[16] M.A. Jabbar, J. Dong, and Z. Liu, "Determination of machine parameters for internal permanent magnet synchronous motors," in Proc. Power Electron., Machines and Drives, 2004, vol. 2, pp. 805-810.

[17] K.W. Lee, D.H. Jung, and I.J. Ha, "An online identification method for both stator resistance and back-EMF coefficient of PMSMs without rotational transducers," IEEE Trans. Ind. Electron., vol. 51, no. 2, pp. 507-510, Apr. 2004.

[18] R. Krishnan, and P. Vijayraghavan, "Fast estimation and compensation of rotor flux linkagein permanent magnet synchronous machines," in Proc. IEEE International Symposium on Ind. Electron., 1999, vol. 2, pp. 661-666.

[19] R. Ramakrishnan, R. Islam, M. Islam, and T. Sebastian, "Real time estimation of parameters for controlling and monitoring," in Proc. IEEE International Electric Machines and Drives Conf., Miami, Florida, 2009, pp. 1194-1199.

[20] S.D. Wilson, G.W. Jewell, and P.G. Stewart, "Resistance estimation for temperature determination in PMSMs through signal injection," in Proc. IEEE International Electric Machines and Drives Conf., San Antonio, TX, 2005, pp. 735-740.

[21] A. Piippo, M. Hinkkanen, and J. Luomi, "Adaptation of motor parameters in sensorless PMSM drives," IEEE Trans. Ind. Applicat., vol. 45, no. 1, pp. 203-212, Jan.-Feb., 2009.

[22] S. Underwood, and I. Husain, "On-line parameter estimation and adaptive control of permanent magnet synchronous machines," IEEE Trans. Ind. Electron., vol. PP, no. 99, pp. 1-9, 2009.

[23] M. Wlas, Z. Krzeminski, and H.A. Toliyat, "Neural-network-based parameter estimations of induction motors," IEEE Trans. Ind. Electron., vol. 55, no. 4, pp. 1783-1794, Apr. 2008.

[24] A.M.N. Lima, C.B. Jacobina, and E.B.D.S Filho, "Nonlinear parameter estimation of steady-state induction machine models," IEEE Trans. Ind. Electron., vol. 44, no. 3, pp. 390-397, Jun. 1997.

[25] J.W. Choi, and S.K. Sul, "Inverter output voltage synthesis using novel dead-time compensation," IEEE Trans. Power Electron., vol. 11, no. 2, pp. 221-227, Mar. 1996.

[26] B. Widrow, and M.A. Lehr, "30 years of adaptive neural networks: percentron, MAdaline, and backpropagation," Proc. of the IEEE, vol. 78, no. 9, pp. 1415-1442, 1990.

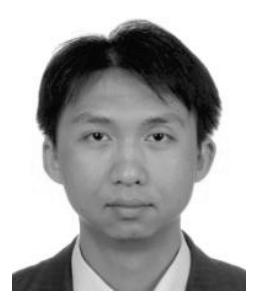

Kan Liu received his B.Eng. degree in automation from the Hunan University, China, in 2005. Then, he started his courses for a joint Master/PHD degree in Hunan University. In 2008, he was supported by China Scholarship Council to go on his study as a joint $\mathrm{PhD}$ student/visiting student at the University of Sheffield, U.K. Currently, he is working in the Department of Electronics and Electrical Engineering at the University of Sheffield. His research interest focuses on brushless AC motor parameters estimation by control theory and nonlinearity compensation for VSI output voltage.

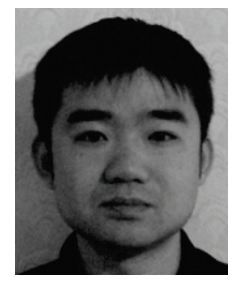

Qiao Zhang received his B.Eng. and M.SC. degrees in the Department of Control Science and Technology from Huazhong University of Science and Technology, Wuhan, China, in 2003 and 2006. In 2008, he was supported by China Scholarship Council to go on his study as a joint PHD student/visiting student at the University of Sheffield, U.K. Currently, he is working in the Department of Electronics and Electrical
Engineering at the University of Sheffield. His research interest focuses on brushless AC motor parameters estimation and machine drives design.

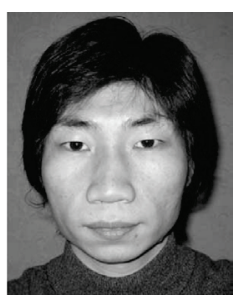

Jintao Chen (M'09) received the B.Eng. and M.Sc. degrees in electrical engineering from Huazhong University of Science and Technology, Wuhan, China, in 2001and 2004, respectively. He is currently a Research Associate in the Department of Electronic and Electrical Engineering, University of Sheffield, Sheffield, U.K., working on the design and analysis of novel permanent magnet brushless machines for automotive applications. From 2004 to 2006, he was an Engineer with Delta Electronics (Shanghai) Company, Ltd.

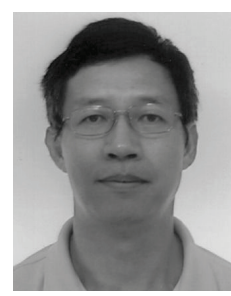

Z. Q. Zhu (M'90-SM'00-F'09) received the B.Eng. and M.Sc. degrees in electrical and electronic engineering from Zhejiang University, Hangzhou, China, in 1982 and 1984, respectively, and the Ph.D. degree in electrical and electronic engineering from the University of Sheffield, Sheffield, U.K., in 1991. From 1984 to 1988, he was a Lecturer with the Department of Electrical Engineering, Zhejiang University. Since 1988, he has been with the University of Sheffield, where he was initially a Research Associate and was subsequently appointed to an established post as Senior Research Officer/Senior Research Scientist. Since 2000, he has been a Professor of Electrical Machines and Control Systems with the Department of Electronic and Electrical Engineering, University of Sheffield, and is currently Head of the Electrical Machines and Drives Research Group and Director of Sheffield Siemens Wind Power Research Centre. His current major research interests include design and control of permanent magnet brushless machines and drives, for applications ranging from automotive, aerospace, to renewable energy. He is a Fellow of IEEE.

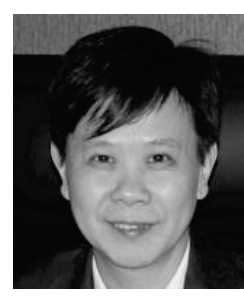

Jing Zhang received his B.Eng., M.Sc. and PHD degrees from Hunan University, China, in 1982, 1984 and 1997, respectively. His research interests are in optimal control, fuzzy control and intelligent control of rotary kiln. He has published more than 100 papers in journals and conferences and was awarded China national second prize of scientific and technological progress. 